University of Zurich

Department of Economics

Working Paper Series

ISSN 1664-7041 (print)

ISSN 1664-705X (online)

Working Paper No. 107

Fair Wages and Effort Provision: Combining Evidence from the Lab and the Field

Alain Cohn, Ernst Fehr and Lorenz Goette

January 2013 


\title{
Fair Wages and Effort Provision: Combining Evidence from the Lab and the Field
}

\author{
Alain Cohn, Ernst Fehr, and Lorenz Goette*
}

January 9, 2013

\begin{abstract}
The presence of workers who reciprocate higher wages with greater effort can have important consequences for labor markets. Knowledge about the determinants of reciprocal effort choices is, however, incomplete. We investigate the role of fairness perceptions and social preferences in workers' performance in a field experiment in which workers were hired for a one-time job. We show that workers who perceive being underpaid at the base wage increase their performance if the hourly wage increases, while those who feel adequately paid or overpaid at the base wage do not change their performance. Moreover, we find that only workers who display positive reciprocity in a lab experiment show reciprocal performance responses in the field, while workers who lack positive reciprocity in the lab do not respond to the wage increase even if they feel underpaid at the base wage. Our findings suggest that fairness perceptions and social preferences are key in workers' performance response to a wage increase. They are the first direct evidence of the fair-wage effort hypothesis in the field and also help interpret previous contradictory findings in the literature.
\end{abstract}

JEL Classification: $\quad$ C93, J31, M52

Keywords:

Fairness Perception, Positive Reciprocity, Field Experiment, Wage Increase

\footnotetext{
* Alain Cohn and Ernst Fehr: University of Zurich, Department of Economics; Lorenz Goette: University of Lausanne, Faculty of Business and Economics. Contact information: alain.cohn@econ.uzh.ch. We would like to acknowledge the generous support of the Swiss National Science Foundation (Grant No. 100014_130127/1 on "The Social Dynamics of Normative Behavior"). We thank Larry Katz and three anonymous referees for helpful comments.
} 


\section{Introduction}

Throughout the history of economics, many prominent economists pointed out that fairness concerns may influence labor market outcomes (Hicks, 1932; Marshall, 1890; Slichter, 1929). ${ }^{1}$ The presence of fair-minded workers who reciprocate higher wages with greater effort may have important consequences for the functioning of labor markets. Concerns for fairness may give rise to non-competitive wage premiums and involuntary unemployment (Akerlof, 1982; Akerlof and Yellen, 1990). Fairness concerns may also change firms' internal pay structure and wage setting over time (Cabrales, Calvó-Armengol and Pavoni, 2008), and they can influence the effects of labor market policies such as minimum wage legislations (Falk, Fehr and Zehnder, 2006).

The nature of how wages affect effort is key to understanding important phenomena in the labor market, such as downward wage rigidity as opposed to general rigidness of wages (Akerlof et al., 1996; Fehr and Goette, 2005). In this paper, we test directly for the psychological mechanisms underlying workers' response to a wage increase in a large-scale field experiment. There is thus far a lack of evidence of how fairness perceptions modulate the effort response to a wage increase. Understanding the psychological mechanisms behind how wages affect effort has important consequences for theory. The simplest way of incorporating fairness concerns is to assume that workers generally consider higher wages to be fairer as in Akerlof (1984); This model predicts a general rigidness of wages with respect to economic conditions. Akerlof and Yellen (1990) take a different approach based on intuitions derived from the social psychology and sociology literature. In their model, they assume workers have a fair reference wage in mind. Wage increases up to the fair wage are assumed to induce workers to exert more effort because higher wages up to this wage limit are perceived to be fairer. In contrast, pay raises above the fair wage are assumed to have no impact on effort because workers already feel fairly treated. The key idea behind this model is that wage increases only affect workers' effort if they alleviate perceived underpayment. This asymmetry has important implications for the labor market. It predicts an asymmetry in how wages react to labor market conditions. While competitive upward-pressures will always raise wages, firms may be reluctant to take advantage of deteriorating labor-market conditions, because pushing the wage below what is perceived to be the fair wage may trigger effort reductions and thus offset the benefit of charging lower wages.

Our paper also contributes to a recent empirical controversy. The evidence from laboratory experiments generally supports the notion that workers exert extra effort on average when they are paid a more generous wage (Brandts and Charness, 2004; Charness, 2000; Charness, Frechette and

\footnotetext{
${ }^{1}$ Slichter (1929) claimed, for example, that companies in the 1920s deliberately pursued a "high wage" policy as they were convinced that paying workers a wage they consider to be fairer would increase productivity, reduce turnover, and prevent labor strikes (p. 431).
} 
Kagel, 2004; Cooper and Kagel, 2009; Fehr, Kirchsteiger and Riedl, 1993; Hannan, Kagel and Moser, 2002). Results from recent field studies is more mixed (Bellemare and Shearer, 2009; Gneezy and List, 2006; Hennig-Schmidt, Sadrieh and Rockenbach, 2010; Kube, Maréchal and Puppe, 2012; Kube, Maréchal and Puppe, forthcoming). These conflicting findings are sometimes taken as evidence that results from the laboratory do not generalize to natural environments, and that the psychological mechanisms identified in the lab may be irrelevant in the field.

We conducted a controlled field experiment to examine how wage increases affect workers' fairness assessment of their pay and how this translates into changes in their effort. Our experiment took place in the context of a sales promotion. A publishing company hired workers for a one-time job. Their task was to distribute copies of a newly launched newspaper at train stations and other public places. We implemented two treatments in collaboration with the publishing company using a within-subjects design. In the baseline treatment, the workers received an hourly base wage of $\mathrm{CHF}$ $22 .{ }^{2}$ In the main treatment, we increased workers' pay by CHF 5 per hour, raising their hourly wage to CHF 27. A comparison of the productivity difference between the two treatments allows us to identify the causal impact of the wage increase on workers' average performance. We also conducted a survey to measure workers' fairness perceptions of their wage during the experiment and two months afterwards. During the follow-up survey the workers also participated in a "laboratory" two-player game with real monetary stakes which allowed us to measure workers' preferences for reciprocity. We can identify and interpret heterogeneous treatment responses by combining the additional data with the data from the field experiment.

We find that the wage increase has on average a positive and significant effect on workers' productivity. But the average effect hides substantial individual heterogeneity in the extent to which workers reciprocate the wage increase. The wage increase causes an increase in the average productivity for those workers who feel underpaid at the base wage. In contrast, adequately or overpaid workers do not respond to the wage increase. The effect is stable over time, and not driven by skill differences that may also determine fairness judgments. This result implies that wage increases up to the level that workers consider to be fair lead to an increase in average effort, while pay raises above this level have no impact on effort. In addition, we find that those workers whom we identify as non-reciprocal individuals in the laboratory two-player game also act in a nonreciprocal manner in the field experiment, i.e., they do not respond to the wage increase, irrespective of whether they feel underpaid or not. In contrast, those workers whom we identify as

\footnotetext{
${ }^{2} \mathrm{CHF} 22$ is roughly the hourly wage that is paid in this area of Switzerland for simple tasks. For example, cleaning ladies in private households typically earn an hourly wage of CHF 20-25. Students who participate in laboratory experiments earn roughly CHF 25 per hour.
} 
reciprocal types in the two-player game provide higher effort in response to the wage increase if they feel underpaid at the base wage.

In view of the fact that the workers knew from the outset that the job for the newspaper's launch was a one-time job that would last only a few weeks, it is unlikely that reputational or repeated game effects affected our results. In principle, the assumption that workers are fairminded is not necessary to explain a positive relationship between wage and effort levels (MacLeod and Malcomson, 1989; MacLeod and Malcomson, 1998; Shapiro and Stiglitz, 1984). These alternative theories rely, however, on the assumption of long-term employment relations, which is clearly ruled out in our setting. ${ }^{3}$ In addition, these theories predict that selfish workers without any preference for reciprocal fairness respond in a reciprocal manner to the wage increase. Our data show, however, that the selfish or non-reciprocal workers do not respond to the wage increase with increased performance. These theories are thus unable to explain why only the workers who exhibit a preference for reciprocal fairness (in the laboratory experiment) respond to the wage increase. Finally, these theories also have problems explaining the role of fairness perceptions. In a long run relationship, the workers who feel well-paid - because they earn a job rent - lose the most when they are fired. Therefore, those who feel well paid or overpaid should react more strongly to a pay raise than those who feel underpaid because the former have more to lose if fired.

Our experiment further develops the methodology of field experiments in labor-market settings (Bandiera, Barankay and Rasul, 2005; Gneezy and List, 2006; Kube et al., 2012; Kube et al., forthcoming). First, we measured workers' fairness perceptions during and after the experiment. This information is important because it helps us understand the relationship between wage changes and fairness perceptions and the link between fairness perceptions and effort choices. A common result in the studies mentioned above is that increases in hourly wages have a small and insignificant average effect on workers' performance. One reason for the lack of a significant effect in these studies may be that the experimenters paid a rather high base wage compared to the market wage for comparable jobs. ${ }^{4}$ We know from our data that higher wages decrease the share of workers who feel underpaid. It is thus possible that only a relatively small number of workers felt underpaid at the base wage in the previous field experiments and that a crucial condition for reciprocal effort choices therefore may have been absent.

\footnotetext{
${ }^{3}$ Strictly speaking, these models are based on the assumption of infinitely repeated interactions between the firm and the workers.

${ }^{4}$ In Kube, Marechal and Puppe (2010a) the base wage was EUR 15, while it amounted to EUR 12 in Kube, Marechal and Puppe (2010b). Students from the University of Karlsruhe (Germany) participated in the field experiment in both studies. The typical hourly wage for research assistants at this university is EUR 8, and the students earned on average EUR 10.5 per hour in previous employment relations. The hourly base wage in the library task of Gneezy and List (2006) was USD 12, while the typical market wage for similar activities was USD 7 (verbal communication by Uri Gneezy). Thus, the base wage in these studies is already quite generous compared to typical alternative employment opportunities. It thus seems possible that only few workers felt underpaid at the base wage.
} 
Second, we measured workers' preferences for reciprocity by conducting a two-player, sequential-move game with them. There is strong laboratory evidence suggesting that individuals' preferences for reciprocity are rather heterogeneous - while many individuals exhibit such a preference, a substantial share of subjects also acts rather selfishly and rarely (or never) returns a favor when doing so is costly (Bellemare, Kroeger and Van Soest, 2008; Bellemare, Kroger and van Soest, 2011; Charness and Rabin, 2002; Fehr et al., 1993). Our laboratory measure of individuals' preferences for reciprocity allows us to go beyond documenting an average effect of a wage increase and helps us understand the reasons behind heterogeneous effort responses.

Third, our study offers better precision due to a large sample. One reason for the lack of a significant effect in the other studies may be the limited statistical power to identify treatment effects due to the relatively small sample sizes with a maximum of 30 subjects per treatment. Although our average effect size is also modest, our larger sample of 196 workers allows us to reject the null hypothesis despite conservative calculations of standard errors that allow the residual to be correlated temporally as well as spatially. Another reason for our significant results may be that our measures for individuals' fairness perceptions, fairness preferences, and individual skill levels enabled us to control for individual heterogeneity. There is ample evidence of heterogeneity in individuals' preferences and skills (e.g. Bandiera et al., 2005; Bandiera, Barankay and Rasul, 2009; Bandiera, Barankay and Rasul, 2010; Bellemare et al., 2008; Fehr and Goette, 2007; Mas and Moretti, 2009), implying that the statistical power may be limited if one cannot control for these individual differences.

Finally, our results also indicate that laboratory and field evidence are not in conflict with each other. If we control for workers' fairness perceptions, workers in the field reciprocate on average higher wages with higher performance - as they do in the laboratory. Likewise, workers who display reciprocal responses in the laboratory are those who also show reciprocal responses in the field. Our results thus also lend support to the notion that laboratory results generalize to field settings. In fact, as we mentioned above, laboratory preference measures even help us better understand the heterogeneity in field responses.

The remainder of this paper is organized as follows. Section II describes the design of our experiment and the setting in which it takes place. Section III presents the empirical findings and Section IV concludes the paper. 


\section{The Experimental Setup}

This section describes the institutional backdrop against which we conduct our field experiment. It also provides a first descriptive look at the data, performs randomization checks and describes our empirical strategy.

\section{II.A The institutional background}

We conducted the field experiment in collaboration with a publishing company during the market launch of a novel daily newspaper. The publishing company commissioned a promotion agency to organize a sales promotion for its new product over a period of three months in the city of Zurich, Switzerland. Workers' task during the sales promotion was to distribute copies of the newspaper to passers-by at public places such as bus stops, train stations and pedestrian areas. Workers could freely choose when to work, but they had to indicate their availability three to four weeks in advance, and once they had signed up for particular shifts they were not allowed to switch or cancel their chosen shifts. Workers had to sign up for blocks of three hours ( $4 \mathrm{pm}$ to $7 \mathrm{pm}$ ) from Monday to Friday. Before the sales promotion began, all workers had agreed to work for CHF 22 per hour.

The workers were managed by team leaders with whom they met at the beginning and end of the shifts at the assigned locations. Due to the size of the sales promotion, the agency divided the city into two equally-sized sectors (I and II) that covered about the same number of locations. Team leaders and workers were sometimes assigned to work in different locations but they always stayed within the same sector. During the shifts, team leaders visited the locations to ensure that the workers did not run out of newspaper copies. They also had to check in an unobtrusive way that workers would not throw copies away. No such incident occurred. Another important task of the team leaders was to record the number of copies each worker distributed during a shift. Team leaders knew how many copies each worker had received at the beginning and if necessary also during a shift and they counted the remaining copies when a shift ended. Neither workers nor team leaders knew that they were part of an experiment.

We deliberately choose a work environment where explicit performance incentives were absent and where reputational or repeated game incentives were unlikely to play a role in order to cleanly identify whether workers voluntarily reciprocate higher wages with greater effort. Workers earned a performance-independent hourly wage. They also had no prospect for future employment at the publishing company. 


\section{II.B The randomized wage increase}

We implemented two treatments. In the baseline treatment, denoted by "CHF22", workers received their regular hourly wage of CHF 22. In the main treatment, denoted by "CHF27", the publishing company raised workers' hourly wage by CHF 5 . The treatments were communicated to the workers shortly before the beginning of a shift with both a postcard and a text message. We used two communication channels to ensure that every worker was informed about the relevant wage. Text messages were sent a few minutes prior to a shift and postcards were handed out by the team leaders at the start of the shifts. The message in treatment CHF22 reminded the workers to retain the straps from the distributed newspaper bundles. The request to keep the straps allowed team leaders to collect the numbers of distributed copies more quickly. In treatment CHF27 the message included the straps reminder and additionally informed the workers about the pay raise. Importantly, the message made it clear that the publishing company, and not the promotion agency, was paying the workers the higher wage: the messages concluded with the name of the publishing company and the postcards bore its logo. Because most workers worked on an irregular basis (e.g., on Monday in one week but on Wednesday and Thursday in another week) we communicated the relevant wage daily, shortly before the beginning of a shift.

The field experiment took place over a four-week period towards the end of the sales promotion. We exploited the spatial division of the city into sectors between which the workers could not move to randomize the two treatments across the two sectors. We chose to randomize the wages on a sector-week level (see Figure 1). Thus, in each of the four experimental weeks the workers in one sector received the higher wage (treatment CHF27), while those in the other sector served as a control and were paid the base wage (treatment CHF22). The weekly rotation of the treatments served two purposes. First, compared to a less frequent rotation, a weekly rotation allows for a more robust identification of confounding time effects, which could have been large if the newspaper had become better known over time. Second, we expected a strong turnover after the second week of the experiment because summer vacation in the schools was beginning at this time. A weekly rotation therefore also helped generate within-subjects variations in pay, enabling us to control for individual-specific factors that affect workers' productivity. While the majority of the workers experienced both wages, it is unlikely that the workers were able to anticipate the wages they were paid during the experimental period. First, there was no communication between workers from different sectors. Second, the weekly rotation of the wages during the experimental period was repeated only once and constituted a small part of the entire sales promotion. Finally, workers had highly irregular workdays making it implausible that they could see through the wage pattern of the experimental period. 
Towards the end of the sales promotion, the promotion agency sent a feedback form to the workers, asking them to state their opinion about the working conditions. One question of particular interest to us asked the workers to rate the fairness of the wages: "I consider the regular (higher) hourly wage of CHF 22 (27) for doing this job to be [1 = very unfair, 2 = moderately unfair, 3 = neither ... nor, $4=$ moderately fair, $5=$ very fair]". This information serves us as a manipulation check, as it allows us to examine the effectiveness of our fairness manipulation. In order to get truthful answers, workers were asked to fill in the form without writing their name on it.

\section{II.C The follow-up survey and laboratory experiment}

Two months after the conclusion of the field experiment, we conducted a follow-up survey among the workers. The survey asked a variety of questions related to temporary work (see Appendix). Participants were paid CHF 7 for completion. They first had to indicate up to three employers from the previous six months (which covered the time period of the sales promotion), and then answer several questions relating to each of their listed employers. The questions of key interest to us asked the participants to state the wage they were effectively paid and the wage they considered to be fair for their work: "What hourly wage did you earn at employer X?" and "What hourly wage would you find appropriate for doing this job at employer X?". By subtracting the answers of the first question from the second, we are able to construct an individual measure of perceived underpayment. The workers had no reason to believe that the survey was in any way connected to the field experiment conducted two months earlier. They did not know that they had been part of an experiment and the survey was administered by researchers whom they perceived to be completely unrelated to the publishing company.

At the end of the survey we measured workers' inclination towards reciprocal fairness by inviting them to participate in a simplified version of the moonlighting game played for real money (Abbink, Irlenbusch and Renner, 2000). This two-player sequential-move game has the important feature that both kind and unkind actions are feasible for both players. In our version of the game, the first-movers could divide CHF 24 in three different ways: they could choose between (i) an unfair allocation (CHF 18 for the first-mover and CHF 6 for the second-mover), (ii) an equitable allocation (CHF 12 for both players), or (iii) a generous allocation (CHF 6 for the first-mover and CHF 18 for the second-mover). The second-movers could then reward or punish the first-movers by assigning up to two positive or negative points, respectively; they could also decide not to assign any points at all. The reward and punishment technology was designed in a way such that one positive (negative) point cost the second-mover CHF 2 and increased (decreased) the first-mover's payoff by CHF 6 . The game was played one-shot; second-mover behavior therefore captures reciprocal fairness without repeated game effects. For the purposes of this study, we assigned all workers to the role of the 
second-mover and elicited their decisions using the strategy method. ${ }^{5}$ We classify the workers as positively reciprocal if they returned more positive points in the generous allocation than in the equitable allocation, or more positive points in the equitable allocation than in the unfair allocation. Thus, to be counted as a positively reciprocal type, the assignment of positive points needs to be a (weakly) increasing function of the second-mover's payoff, with a strictly positive slope in at least one of the two comparisons (unfair vs. equitable, equitable vs. generous).

\section{II.D Descriptive statistics and randomization checks}

Table 1 presents the summary statistics of the data used in this paper. We observed 196 individuals during the four experimental weeks of the sales promotion. More than 70 percent of the workers were female. Workers were between 16 and 42 years old, with an average age of 22.5 years. Most of them were Swiss citizens. On average, they completed 6.5 shifts and distributed 228 newspaper copies per hour. Table 1 also shows that the experimental conditions were well balanced within individuals. Workers' median exposure to the higher wage was 50 percent of the shifts; the $25^{\text {th }}$ percentile of the distribution was 42 percent, and the $75^{\text {th }}$ percentile was 66 percent.

Turning to the fairness perception of wages, we asked in the follow-up survey what wage workers would consider appropriate for this type of job. The average reply was CHF 1 more than the CHF 22 paid in the baseline treatment. This judgment, however, is not uniform, as can be seen in the histogram in Figure 3. It shows the distribution of the difference between what workers considered to be the appropriate wage and the base wage of CHF 22. Slightly less than half of the workers considered the base wage as the appropriate wage. The majority of the workers (53 percent) perceived themselves to be underpaid at the base wage of CHF 22, with a sizable group of workers (20 percent) perceived CHF 25 to be the appropriate wage.

The last panel in Table 1 displays the average back transfer in the moonlighting game. In response to the generous allocation of "CHF 6 for the first-mover, CHF 18 for the second-mover" the workers spent an average of 0.89 positive points to increase the first-mover's payoff. They spent on average 0.25 positive points if the first-mover chose the equitable allocation (CHF 12, CHF 12). If the first-mover chose the unfair allocation (CHF 18, CHF 6), the workers spent 0.56 negative points to reduce the first-mover's payoff. Table 1 also displays the results separately for the reciprocal $(N=$ 77) and the non-reciprocal $(N=41)$ participants. There are large quantitative differences between these two groups. This is because many of the non-reciprocal individuals act strictly selfish, never

\footnotetext{
${ }^{5}$ The choices of the first-movers in the moonlighting game were collected through a survey mailed to a random sample of students at the University of Zurich around the same time.
} 
spending any points. Others display a concern for efficiency and always transfer the same number of positive points.

We present various checks that verify that we successfully randomized subjects to treatment conditions. As explained above, the assignment of workers to shifts and locations was organized in a way that made it nearly impossible for them to selectively pick shifts in treatment CHF27. Nevertheless, we need to verify whether the worker characteristics in the two treatments were identical, because imbalances in these characteristics could also create treatment differences in effort. It is therefore important to know whether workers' characteristics are balanced across treatments. Table 2 shows that this is the case. Worker characteristics in the two treatments are statistically identical for every dimension we measured (e.g., underpayment judgments, age, gender, etc.).

Most importantly, we need to establish that there was no selectivity with respect to the number of shifts worked as a function of the treatment, as this would complicate our empirical analysis below. As we explained earlier, the rule was that the workers had to sign up for shifts well in advance. This makes it difficult for workers to select into treatments. The results in Table 3 confirm that there was no selectivity. The table reports the results from a regression where the number of shifts a worker completed in each treatment is the dependent variable. The results show that the workers worked on average the same number of shifts in the two treatments. They worked 3.1 shifts in the CHF22 treatment; the dummy for the CHF27 treatment is small and far from significant: it is equal to 0.18 , with a standard error of 0.13 in column (1). Thus, we would have been able to detect even small differences of 0.26 shifts across groups, which is less than 5 percent of the 6.2 shifts worked altogether. We consider this a "tightly estimated zero": the number of shifts worked in the two treatments is statistically indistinguishable. This result also holds if we control for individual fixed effects (see column 2 in Table 3).

In Table 4 we check the randomization to treatments from a different angle. The promotion agency had difficulties filling the available shifts; shifts remained vacant in roughly 20 percent of cases. It would have been easier for the company to fill the higher wage shifts if workers had selfselected into treatment CHF27. Table 4 shows, however, that this was not the case. In this table the number of unfilled shifts in each sector for each day of the study is the dependent variable. The results show that the coefficient of the CHF27 dummy is close to zero and insignificant, indicating that treatment CHF27 had no effect on the share of unfilled shifts. Thus, there was no selectivity into the number of shift worked. 
We also examine whether the experimental conditions affect our underpayment measure and workers' willingness to reciprocate in the moonlighting game. It is important to check whether a higher exposure to one of the treatments influenced our underpayment measure (i.e., the difference between the wage deemed to be appropriate and the base wage) and our measure of reciprocity. If they did, we could not use these measures as independent variables in our regressions described below. Column (1) in Table 5 shows that the fraction of shifts during which a worker is exposed to treatment CHF27 has no effect on our underpayment variable. Thus the small differences in exposure to the CHF27 treatment did not affect subsequent fairness judgments of wages. Columns (2) - (4) in Table 5 examine whether the exposure to the CHF27 treatment affects workers' behavior in the moonlighting game for the three possible transfers of the first-mover. Since the choices in the three cases are probably highly correlated, this needs to be taken into account when calculating the standard errors. We therefore estimate the three equations as seemingly unrelated regressions, thus allowing arbitrary correlation in the residual across the three choices. Taken individually, the results in each of the columns show no significant influence of the CHF27 treatment on workers' second-mover behavior. We also perform a joint test of the hypothesis that the exposure to the CHF27 treatment did not affect back transfers in any of the three cases by estimating all three regressions using a seemingly unrelated regression model. The $p$-value of the hypothesis of no effect in all three equations is 0.58 . We thus conclude that variations in the exposure to the higher wage neither influence our underpayment measure nor workers' behavior in the moonlighting game, and this thus allows us to use these measures as independent variables in our empirical analysis.

\section{II.E The empirical strategy}

Approaching and addressing passers-by requires effort. Therefore, the number of copies distributed is our measure of individual effort. Since we have shown in Tables 3 and 4 that our treatment did not affect the number of shifts worked, this implies that there is no selectivity into work with respect to the treatment. We can focus directly on labor supply conditional on having chosen to work. We first estimate the average treatment effect of the wage increase on workers' performance using the following regression model:

$$
\log \left(y_{i k t}\right)=\beta_{0}+\beta_{1} \mathrm{I}(\text { CHF27 })_{k t}+\lambda_{k}+\delta_{t}+\epsilon_{i k t},
$$

where the dependent variable is the log of the number of hourly copies distributed by worker $i$ at location $k$ on day $t$. Our key exogenous variable is the wage condition in which a worker was working, which is represented by the treatment indicator CHF27 for the high wage condition. Its coefficient $\beta_{1}$ (multiplied by 100) can thus be interpreted as the percentage change in workers' performance that is caused by the wage increase. We include an exhaustive set of fixed effects $\lambda_{k}$ as 
controls for the location at which a worker $i$ worked on day $t$. We also include day fixed effects $\delta_{t}$ for each day of the experiment.

Our experimental wage increase guarantees that the treatment indicator is uncorrelated with the residual $\epsilon_{i k t}$ and that the OLS estimator will satisfy the conditional-mean independence needed for convergence to the true parameter. It does not, however, imply that the residual is uncorrelated across observations, thus raising potential issues with the standard errors of the estimated coefficients. Standard OLS procedures require that the residual be independent between any two observations. Two potential sources of correlation for the residual in our application are serial correlation within an individual, and correlations among the residuals of spatially close observations on the same day. Temporary, but auto-correlated shocks to an individual's motivation may induce serial correlation in an individual's performance on the job and thus render the assumption of independence of the residuals within an individual invalid. The residuals may also be spatially correlated because one could imagine that if a swarm of commuters heads in one direction, this affects the pick-up rate of the newspaper of spatially close workers in a similar way. This introduces a spatial correlation into the residuals of geographically close workers (Conley, 2008). In this case, because the residual is uncorrelated with the treatment, the treatment effect can still be estimated consistently by using OLS. However, the standard errors provided by standard OLS routines will be wrong, and, potentially, biased downward (Angrist and Pischke, 2009). We use Hsiang's (2010) non-parametric correction for spatial and temporal correlation in order to correct for the two potential problems and to obtain the correct standard errors without imposing further restrictions on the covariance matrix. This procedure is very similar to multi-way clustering in that it allows for any form of spatial and serial correlation, but uses a kernel estimate of the covariance matrix in which spatially close observations can be defined. We chose a radius of 3 kilometers in our application, and place no constraints on the number of lags for the individual. ${ }^{6}$

To take account of individual differences, we also estimate a variant of equation (1) with individual fixed effects $v_{i}$ included:

$$
\log \left(y_{i k t}\right)=\beta_{0}+\beta_{1} \mathrm{I}(\text { CHF 27) })_{k t}+v_{i}+\lambda_{k}+\delta_{t}+\epsilon_{i k t}
$$

\footnotetext{
${ }^{6}$ An omnibus way to fix this problem would be to cluster observations along two dimensions: individuals and week $\times$ region. However, this correction is valid asymptotically, as the number of week $x$ region cluster gets large. We only have 8 week $\times$ region cells and thus this is unfeasible (we are grateful to an anonymous referee for pointing this out). Our correction allows arbitrary correlations within an individual, and spatially correlated residuals across different individuals on the same day. The only difference between our correction and the one suggested here is only that ours does not allow the residual of individual $i$ on day $t$ to be correlated with the residual of another individual on a different day in that week. It is difficult to imagine how one newspaper distributed today by one vendor could have an effect on the number of newspapers another vendor would distribute in the future. Thus, we are comfortable restricting ourselves to the slightly more restrictive formulation we have chosen here.
} 
Including the individual fixed effects is not strictly necessary, as the treatments are randomized. But it provides a way to check whether the precise specification of the model affects the conclusions of any of our results and also potentially provides more precision.

In a second step of the analysis, we investigate individual heterogeneity in the treatment effect. Specifically, we examine how workers' perceived fairness of the base wage affects their performance response to the wage increase. In keeping with our specifications above, we estimate the following regression model:

$$
\log \left(y_{i k t}\right)=\beta_{0}+\beta_{1} \mathrm{I}(\text { CHF27 })_{k t}+\beta_{2} \mathrm{I}(\text { CHF27 })_{k t} \times \Delta_{\mathrm{i}}+\beta_{3} \Delta_{\mathrm{i}}+\lambda_{k}+\delta_{t}+\epsilon_{i k t},
$$

where $\Delta_{\mathrm{i}}$ measures worker i's perceived underpayment, i.e., the difference between what worker $i$ considered to be a fair wage for this job and the wage he was paid in the baseline treatment. In this case, $\beta_{1}$ (multiplied by 100) can be interpreted as the percentage change in workers' performance that is triggered by the wage increase if the worker feels adequately paid in the baseline treatment, i.e., if $\Delta_{\mathrm{i}}=0$. The coefficient of the interaction term $\beta_{2}$ indicates the extent to which perceived underpayment affects workers' response to the wage increase. We also estimate the same equation including individual fixed effects rather than a control for $\Delta_{\mathrm{i}}$ :

$$
\log \left(y_{i k t}\right)=\beta_{0}+\beta_{1} \mathrm{I}(\text { CHF27 })_{k t}+\beta_{2} \mathrm{I}(\text { CHF27 })_{k t} \times \Delta_{\mathrm{i}}+v_{i}+\lambda_{k}+\delta_{t}+\epsilon_{i k t} .
$$

This specification allows for fully flexible control for possibly non-linear effects of $\Delta_{\mathrm{i}}$ on performance.

\section{Results}

The literature on social preferences suggests that the extent to which higher wages lead to higher effort depends on whether and how higher wages are associated with an increase in the perceived fairness the wage. We therefore begin the exposition of our results by presenting the effect of the wage increase on workers perceived fairness of their wage. We then turn to the average treatment effect of the wage increase on worker productivity, and assess the robustness of this result. Finally, we probe deeper into the psychological mechanisms that underlie the observed pattern in the data.

\section{III.A The impact of the wage increase on workers' perceived fairness of the wage}

Data from the feedback form collected during the experiment point to a strong impact of the wage increase on workers' perceived fairness of their pay. Panel $(A)$ in Figure 2 shows that roughly 30 percent of the workers perceived the base wage as unfairly low, while Panel (B) in this figure indicates that less than 2 percent reported the same for the higher wage. Moreover, comparing the two panels reveals that there is a clear shift to a fairer assessment of pay in treatment CHF27 $p<$ 
0.01 , Wilcoxon signed-rank test). ${ }^{7}$ However, there is strong heterogeneity in the fairness perception of the base wage. The strongest shift in the distribution of fairness assessments comes from the bottom end of the distribution, meaning that the higher wage had the largest impact on those workers who considered the base wage to be unfairly low. But there is also a large group of workers for whom the higher wage could not improve their perceived fairness of the wage; those workers already perceived the base wage as rather fair and considered the higher wage to be equally fair.

As discussed earlier, in the follow-up survey conducted two months after the experimental period of the sales promotion we find similar individual heterogeneity in fairness perceptions. Figure 3 shows that more than half of the workers perceived themselves to be underpaid at the base wage, implying that a large number of the workers accepted the job even though they thought that pay was unfairly low. About one-third of the workers considered themselves to be adequately paid, while only few (12 percent) thought they were overpaid for this job. Because we know from every worker the wage that is considered as fair ("appropriate") we can also calculate how many workers felt underpaid at CHF 27. We find that only 3 out of 119 individuals felt underpaid at this wage. Thus, we have established

Result 1: The wage increase is associated with an increase in the perceived fairness of pay on average. However, there is strong heterogeneity in workers' fairness perceptions. The wage increase raises the perceived fairness of pay particularly among workers who evaluate the base wage as unfairly low.

\section{III.B The average treatment effect of the wage increase on workers' performance}

We now turn to the behavioral effects of the wage increase and begin by investigating its average impact on performance. First evidence is shown in Figure 4, which displays the average performance in the two treatments. For ease of comparison, we subtract the mean productivity at the location in question for each observation; a zero thus corresponds to the average performance in a particular location. Since we take the natural logarithm of these numbers, they can be interpreted directly as the percentage differences to the location mean. The figure suggests a positive average treatment effect. In response to the wage increase, workers increased their performance by about 4 percent on average. The standard errors of the means are rather small, and error bands do not overlap across treatments, possibly indicating that the effect is statistically significant. However, these standard errors do not exploit the other controls available to us and are possibly biased due to temporal and spatial correlations within the residual, as explained in section II.E. We thus turn to the regression

\footnotetext{
${ }^{7}$ All $p$-values reported in this paper are two-sided.
} 
estimates that resolve these issues. The first column of Table 2 shows the estimation results for equation (1). The estimated average treatment effect of the wage increase on workers' performance is 3.7 percent. Column (2) of this table shows the estimates with individual fixed effects based on equation (2). The point estimate of the average treatment effect is slightly lower, but still significant at the 5-percent level. Thus, we have established:

Result 2: $\quad$ The wage increase has a positive and significant impact on workers' performance on average.

The point estimates we obtain are roughly in line with the point estimates founds in earlier studies that use comparable treatments (Gneezy and List, 2006; Kube et al., 2012; Kube et al., forthcoming). However, the previous studies did not find significant effects - perhaps because of the smaller sample sizes and the use of between-subject designs.

Next we present some robustness checks for Result 2. Some studies suggest that gift exchange has an emotional component that may dissipate over time with the consequence that the extra effort may wear off (Falk, 2007; Gneezy and List, 2006). We address this hypothesis by including into equation (1) both a control variable for the number of previous shifts in treatment CHF27 and its interaction with the treatment dummy. Column (1) of Table 7 shows the results when we allow the treatment effect to be a function of workers' previous experiences with the higher wage. The coefficient on treatment CHF27 can be interpreted as the average impact of the wage increase when workers encountered the increase for the first time. The estimate is positive and significant, and somewhat larger than the estimate of the overall treatment effect. However, there is little evidence on a diminishing gift exchange effect, as indicated by the small and insignificant coefficient on the interaction term and considering that on average the workers worked three shifts in each treatment. Thus, taking into account the number of previous shifts in treatment CHF27 does not support the conjecture that workers' initial responses to the higher wage are systematically different than their subsequent responses.

In a further step, we investigate whether the performance difference between the two wage conditions is driven by workers being disappointed about falling back to the base wage after having encountered the higher wage. Because some studies indicate that reference points and loss aversion affect labor supply (Abeler, Falk, Goette and Huffman, 2011; Fehr and Goette, 2007), one may argue that experiencing the higher wage causes workers to upwardly adjust the wage they think they are entitled to, and consequently, they may consider the removal of the wage increase as a loss in earnings and because of loss aversion they adjust their effort more strongly than when they receive 
the wage increase. We have already established that workers' duration of exposure to the higher wage did not influence their perceived underpayment at the base wage. We proceed on investigating reference point effects by estimating equation (1) but excluding observations (and also the subsequent ones) that occurred when workers switched back to the base wage. Column (2) of Table 7 shows a positive and significant coefficient on treatment CHF27 that is even larger than the estimated coefficient for the total sample. Thus, if anything, workers were more responsive to introducing than removing the higher wage. Taken together, the results suggest that the wage increase was perceived as a gift that triggered positive reciprocity in the form of higher effort.

\section{III.C Heterogeneous treatment effects of the wage increase on workers' performance}

In contrasts to reciprocity models, a key ingredient of the fair wage-effort hypothesis by Akerlof and Yellen (1990) is that only the workers who feel underpaid at the base wage should respond to the higher wage with higher effort. We therefore investigate whether heterogeneous fairness perceptions lead to heterogeneous effort responses to the wage increase. Figure 5 displays the treatment effect separately for two types of workers: the workers who considered the base wage to be fair and those who considered it to be unfairly low. The figure shows that the workers who felt adequately paid at the base wage (including the few who felt overpaid) did not react to the wage increase at all, while those who perceived the base wage as inadequately low increased their performance by about 7 percent. Judging by the error bands, the figure suggests that the impact of the wage increase is significant for the second group, but not for the first. To better understand the heterogeneity in the treatment effect we estimate equation (3) where we include an interaction term between treatment CHF27 and the underpayment measure, denoted by $\Delta_{i}$. Because we need to restrict the sample to individuals who completed the follow-up survey, we first replicate the average treatment effect without taking account of the underpayment perceptions, in order to show that the workers who completed the follow-up survey responded in exactly the same way to the wage increase as all others did. As can be seen in column (1) of Table 8, the point estimate on treatment CHF27 is identical to that in column (1) of Table 6. Column (2) of Table 8 now presents the estimates of equation (3) that includes the interaction of treatment CHF27 with $\Delta_{i}$. The estimate of $\beta_{1}$ is not significant, implying that the workers who felt adequately paid at the base wage (i.e., $\Delta_{i}=0$ ) did not respond to the wage increase. However, workers who felt underpaid responded quite strongly. The estimate of 0.019 for $\beta_{2}$ is highly significant and implies that workers' performance response to the wage increase gets stronger with every Swiss franc that a worker felt underpaid at the base wage. We also estimate the model with individual fixed effects as described in equation (4). In this specification, reported in column (3) of Table 8 , the point estimate of $\beta_{1}$ is again close to zero and insignificant. However, the point estimate of $\beta_{2}$ is positive and significantly 
different from zero $(p=0.01)$. It implies that for every Swiss franc that a worker felt underpaid, workers' response to the higher wage increases by 0.018 . Thus, for a worker who considered the fair wage to be CHF 27 (as many did), the response is $0.005+5 \times 0.018=0.095$ or 9.5 percent; this effect is almost three times as large as the average treatment effect. Thus, the workers who felt underpaid at the base wage responded very differently to the wage increase than those who felt adequately paid - a finding that highlights the importance of heterogeneous fairness perceptions in our understanding of the mechanism behind the motivational effects of pay raises. We summarize this finding in

Result 3: $\quad$ There is strong heterogeneity in workers' response to a wage increase. Workers who perceive themselves to be underpaid at the base wage raise their performance significantly when they are paid a higher wage, while workers who feel adequately paid or overpaid at the base wage do not respond to a wage increase.

In the following, we present a robustness check for Result 3 that examines the role of workers' individual ability in the treatment effect. We are particularly interested in the hypothesis that high ability workers have different underpayment perceptions compared to low ability workers. If, for example, high ability workers are more likely to perceive themselves to be underpaid, the interpretation of the positive impact of perceived underpayment on the performance response to the wage increase becomes more ambiguous - perhaps it is workers' ability and not their fairness perceptions that drive the underpayment effect.

We first examine whether there is a correlation between a measure of individual ability and underpayment perceptions. We use the worker fixed effects $v_{i}$ from equation (2) as a measure of worker ability. Workers with a high $v_{i}$ are, on average, more productive than those with a low $v_{i}$. We find that the correlation between workers' individual $v_{i}$ 's and their underpayment measure is close to zero and insignificant (Spearman rank correlation: 0.029, $p=0.75$ ). This provides a first hint that ability is an unlikely explanation for the underpayment effect. We further examine the role of ability more formally in Table 9. For ease of comparison, column (1) of this table presents again the underpayment effect. To examine the role of ability, we divide the workers into two groups: workers with a $v_{\mathrm{i}}$ above the median (= high-ability), and those with a $v_{i}$ below the median (= low-ability). We then re-estimate equation (1) but include a dummy variable for the high-ability workers as well as an interaction of this dummy variable with the indicator for treatment CHF27. The results in column (2) of Table 9 show that the coefficient of the interaction term is insignificant, indicating that compared to the low-ability workers the high-ability workers did not respond differently to the wage increase. We conclude this robustness check by estimating a model that includes the underpayment variable, 
the ability variable, as well as their interactions with the treatment indicator. The results in column (3) of Table 9 demonstrate again that workers' abilities do not drive the underpayment effect. While the point estimate of the underpayment interaction remains robustly positive and significant, the ability interaction is still insignificant. Taken together, highly skilled workers did not respond differently to the higher pay than did less skilled workers. Moreover, controlling for ability does not affect the relationship between perceived underpayment and workers' performance response to the higher wage.

The way perceptions of fairness mediate the behavioral response to treatment CHF27 is consistent with the fair-wage effort hypothesis (Akerlof and Yellen, 1990). This hypothesis stipulates that reciprocal workers respond to an improvement in their pay by increasing effort up to the point where they feel treated fairly. However, a necessary condition for this to be true is that individuals have a preference for reciprocal fairness. Our survey experiment shows that there is considerable heterogeneity in reciprocity concerns between individuals: while 77 participants can be classified as reciprocal in the moonlighting game, 44 cannot: their back transfers do not depend on the generosity of the first-mover. Thus, if our "laboratory" measure of reciprocal fairness captures individuals' general propensity to reciprocate favors, the performance response to the higher wage and the way in which this is mediated by the perceived fairness of the wage should also differ between these two groups.

To test this hypothesis, we first check whether underpayment perceptions differ between the two groups. The test results show that reciprocal workers and non-reciprocal workers do not differ in their underpayment judgments (Kolmogorov-Smirnov test, $p=0.92$ ). Thus, any difference in the impact of underpayment perceptions on the performance response to the wage increase cannot be due to such differences. Next, we estimate equation (4) separately for the reciprocal and the nonreciprocal workers. ${ }^{8}$ Table 10 displays the results. We first turn to the estimates for the reciprocal individuals in column (1). As before, we find no significant effect of the wage on performance when workers perceived themselves to be adequately paid or overpaid. The coefficient $\beta_{1}$ on the main effect of treatment CHF27 is small and insignificant. However, we find that fairness perceptions play an even stronger role in workers' performance response to the wage increase. The coefficient of the interaction term, $\beta_{2}$, is now 0.028 , implying that workers' performance response to the higher wage increases by 0.028 with every Swiss franc that a worker felt underpaid at the base wage. Thus, an individual who felt underpaid by CHF 5 at the base wage displayed a performance response of 14

\footnotetext{
${ }^{8}$ We also estimated interaction effects for reciprocal and non-reciprocal workers, but we decided to report the results in separate equations for expositional simplicity. Estimating interaction effects yields the same conclusions. However, because the reciprocal and non-reciprocal workers may differ in dimensions other than reciprocal fairness that could affect productivity, we estimate the model with individual fixed effects as described in equation (4) in order to control for such unobservable differences.
} 
percent which is almost four times as large as an average individual. For reciprocal individuals, the performance response to a wage increase therefore strongly depends on their fairness perceptions. By contrast, the estimates for the non-reciprocal individuals in column (2) show no evidence that their performance response depends on fairness perceptions. The point estimate is even negative, but not significant. The data reject the hypothesis that fairness perceptions mediate the response to the wage increase the same way for reciprocal and non-reciprocal individuals, i.e., that $\beta_{2}^{R}=\beta_{2}^{N R}$ ( $p$ $=0.01$ ). Notice, however, that the non-reciprocal group exhibits a more blurred estimate of the response to the wage increase in the absence of underpayment. The estimate of $\beta_{1}^{N R}=0.018$ with a standard error of 0.023 . Yet, even when taking this blurriness into account, we reject the hypothesis that $\left(\beta_{1}^{R}, \beta_{2}^{R}\right)^{\prime}=\left(\beta_{1}^{N R}, \beta_{2}^{N R}\right)^{\prime}$ in a joint F-test $(p=0.04)$. Furthermore, we easily reject the hypothesis that the wage increase does not affect the reciprocal group of workers $(p=0.02)$, while we cannot reject the null of no response for the non-reciprocal workers. Thus, it is only the reciprocal group of workers who respond to the wage increase, and this response takes the form of the fair-wage effort hypothesis. This pattern is statistically different from what we observe for the non-reciprocal workers, even though we cannot characterize the non-reciprocal workers' behavior with much precision. For this last group, our best interpretation is that they do not respond to the wage increase. We summarize these results in

Result 4: There is considerable heterogeneity in workers' preferences for reciprocal fairness. Underpaid reciprocal workers strongly increase their performance when they are paid a higher wage, while the pattern is significantly different for non-reciprocal workers: even when feeling underpaid, non-reciprocal workers do not respond to a wage increase.

This result thus lends further support to our interpretation of the fair-wage effort mechanism. It is also important because it provides evidence against the interpretation that the observed responses are driven by repeated-game effects, and that the results should not be interpreted as evidence of social preferences. In a repeated game, even the selfish types have an incentive to raise effort because it may pay to do so if one considers the employer's response in the future. By contrast, we do not find that the non-reciprocal workers respond to the wage increase at all, suggesting that they do not see any gain from working harder in response to the higher wage.

\section{Conclusion}

The conditions under which workers reciprocate higher wages with higher effort are of considerable importance for the functioning of labor markets (Akerlof, 1982; Akerlof and Yellen, 1990). In this paper, we combine a field experiment that examines the impact of a wage increase on workers' 
performance with both survey measures of workers' fairness perceptions and a laboratory measure of workers' preferences for positive reciprocity. The combination of these tools enables us to acquire deeper insights into the role of these factors for workers' effort response to wage increases. Our results suggest that the perceived fairness of the base wage plays an important role in mediating the response to a wage increase. Workers who perceive being underpaid at the base wage increase their effort in response to a wage increase, while those who feel fairly paid or overpaid do not respond to the higher wage. The role of fairness perceptions helps us reconcile our results with previous evidence that did not find a significant effect of a wage increase on performance (Gneezy and List, 2006; Kube et al., 2012; Kube et al., forthcoming). In these studies the base wage was already rather high relative to wages in alternative jobs, meaning that workers may have perceived the base wage as already quite fair.

We also show that the performance response to the wage increase and the role of fairness perceptions is robust to controls for workers' skill levels. We find that it neither increases nor significantly decreases over time, in contrast to Gneezy and List (2006), suggesting that their result does not easily generalize across occupations. In addition, we identify another important source of heterogeneity in workers' effort response to a wage increase. We find that only those workers whom we identify as reciprocal individuals in a laboratory two-player game respond to the wage increase with higher performance, while those whom we identify as non-reciprocal and selfish leave their performance unchanged irrespective of whether they feel underpaid or not.

Because the workers knew that their job will last only a few weeks, reputational or repeated game effects are unlikely to explain their behavior. Moreover, theories that explain the observed gift exchange exclusively in terms of workers' self-interest have problems explaining the important role of fairness perceptions and reciprocal preferences for workers' reciprocation behavior. Reputation incentives should be effective for selfish workers as well. Yet, our results show no evidence than selfish workers react to the wage increase, thus also making repeated-game interpretations less plausible. In this sense, our results also illustrate the usefulness of combining laboratory and survey methods with field experiments in order to identify psychological mechanisms that may be at work in the field.

The insights gained from this study point to new directions for future research. Our study shows that the composition of the work force in terms of perceived underpayment and reciprocity crucially determines the effectiveness of higher wages. This suggests that much can be gained by studying the determinants of workers' fairness perceptions and how firms can shape them through wage and non-wage instruments. Kube et al. (2012) have taken an interesting step in this direction. Their data indicate that non-monetary gifts or thoughtfully prepared cash gifts elicit much stronger 
performance responses from the workers than simply giving money. This suggests that the extent to which workers reciprocate a gift from their employer depends not only on the economic value of the gift but also on its signaling value. Finally, little is known about how compensation executives can "manage" workers' fairness perceptions in a productivity enhancing way. 


\section{Figures and Tables}

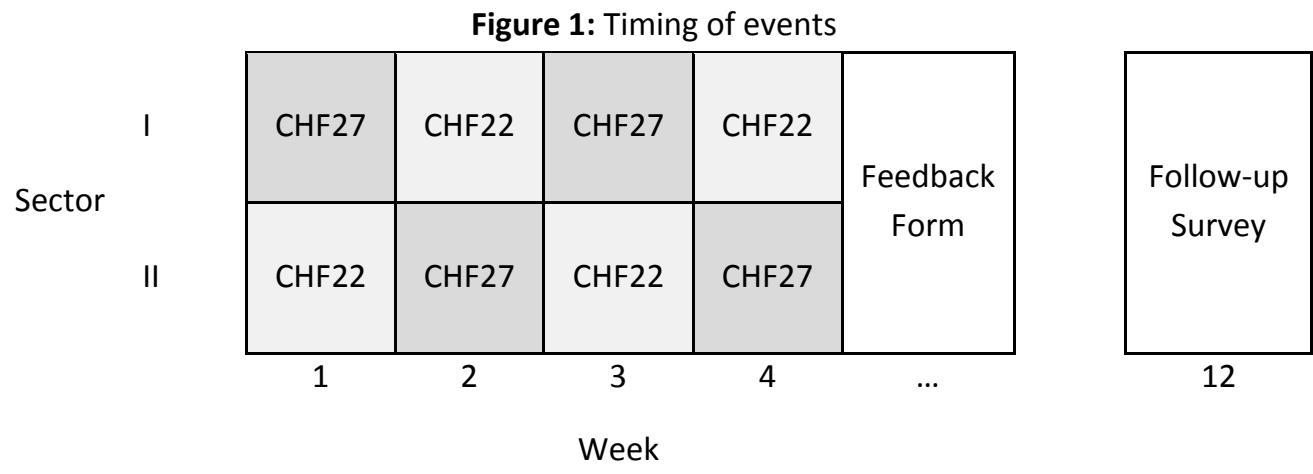

This figure visualizes the two phases of the study. The first phase consists of the randomized wage increase that took place during the four experimental weeks of the sales promotion and a feedback form that was administered towards the end of the experimental period. We randomized wages on a sector-week level. Thus, for a given week the workers in one sector received the higher wage (treatment CHF27), while those in the other sector served as a control and were paid the base wage (treatment CHF22). In a second phase, we invited the workers to participate in a survey on part-time work that allowed us to measure both their perceived underpayment at the base wage and their preference for reciprocal fairness.

Figure 2: Workers' fairness assessments of the base and higher wage
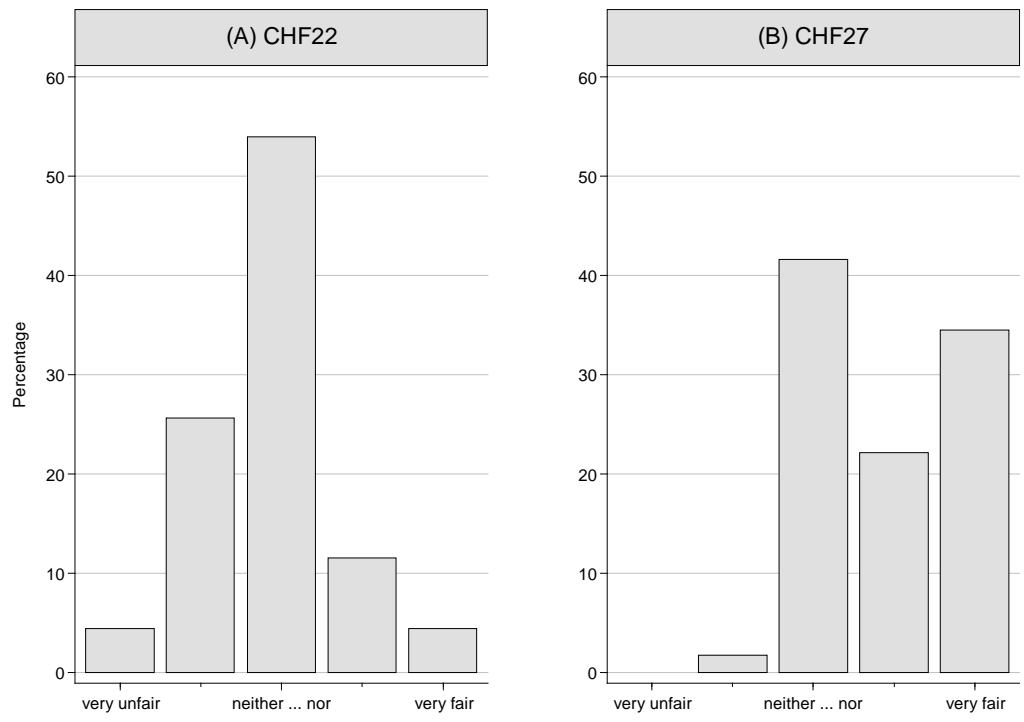

The figure shows workers' fairness ratings of the base wage (CHF22) and the higher wage (CHF27) on a 5-point scale using data from the anonymous feedback form. 
Figure 3: Workers' perceived underpayment at the base wage

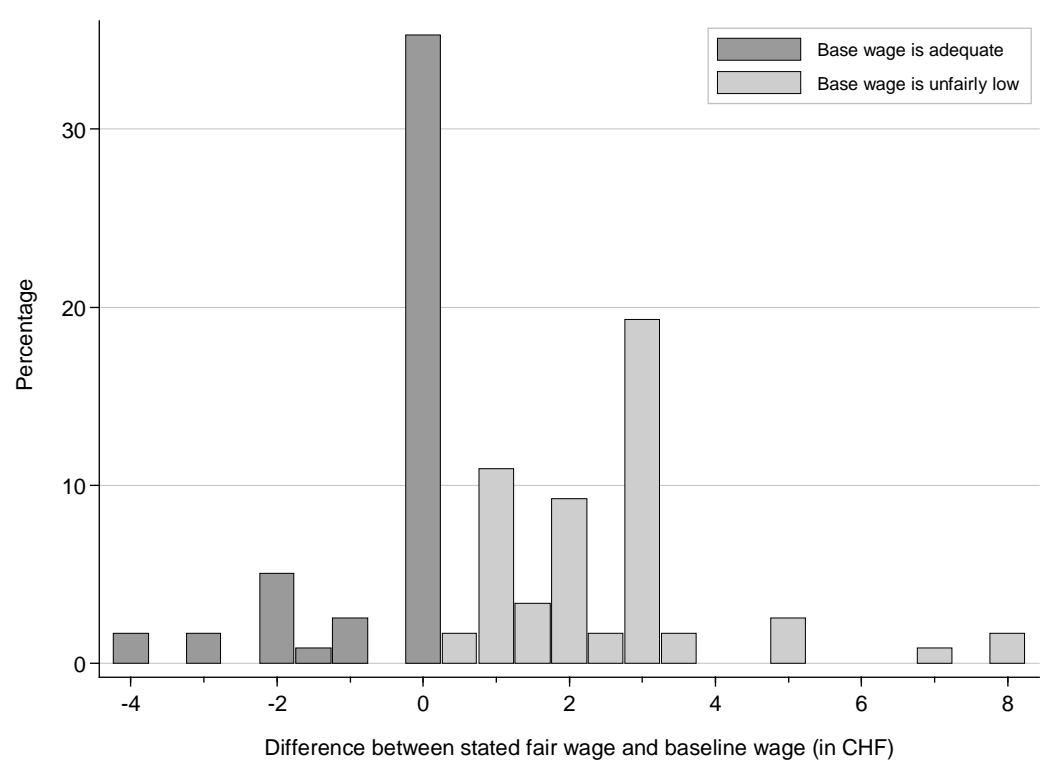

This figure shows a histogram of the difference between what the workers considered to be the appropriate wage and the base wage of CHF 22 per hour. A positive number indicates that a worker felt underpaid at the base wage, while a negative number indicates that the worker perceived to be overpaid for this job. Bins are in steps of CHF 0.5.

Figure 4: Average treatment effect of the wage increase on workers' performance

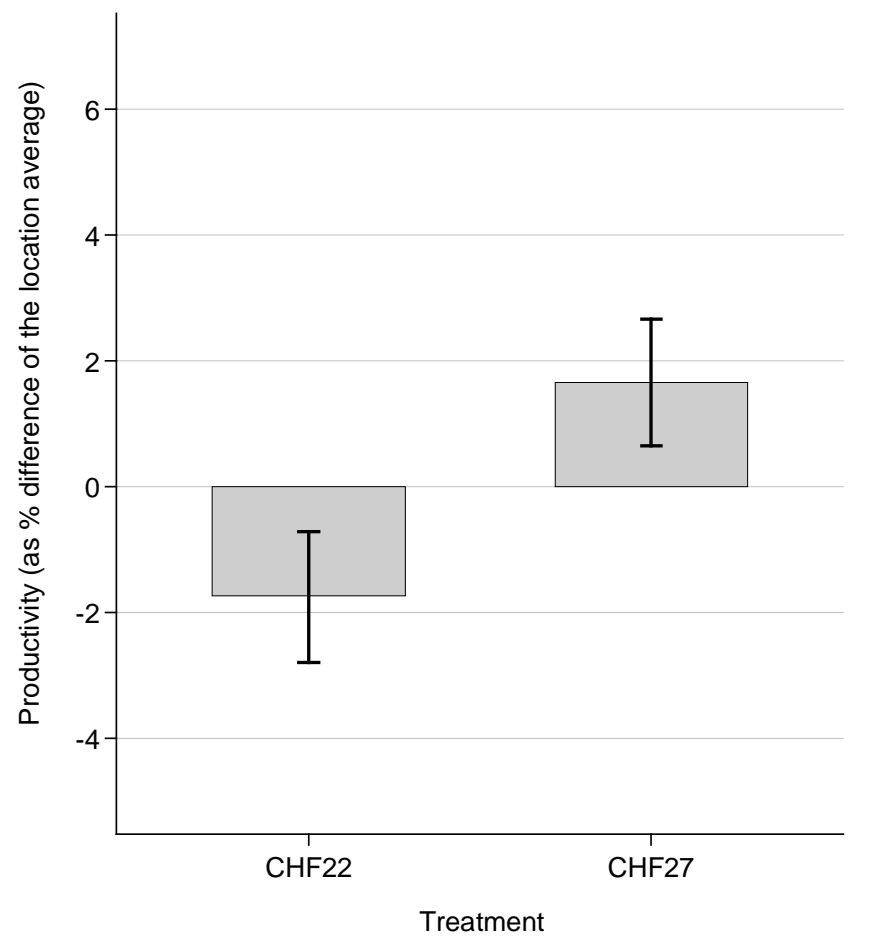

This figure shows workers' average performance and standard error of the mean in each treatment. Performance is measured as the hourly copies distributed normalized by the average hourly copies distributed at the location. 
Figure 5: Heterogeneous treatment effect of the wage increase on workers' performance

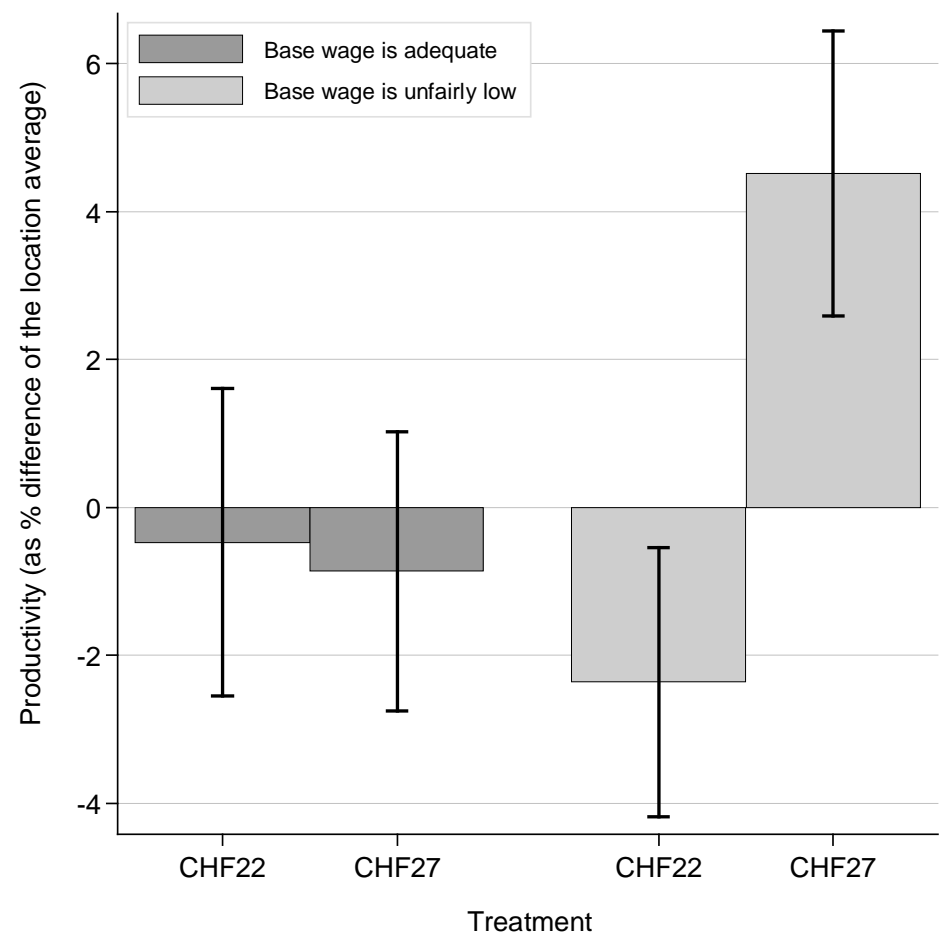

This figure displays workers' average performance and standard error of the mean in each treatment, shown separately for the workers who felt adequately paid at the base wage and those who felt underpaid. Workers' performance is the number of hourly copies distributed normalized by the average productivity at the location. 
Table 1: Descriptive statistics

\begin{tabular}{lccc}
\hline Variable & Mean & SD & $\mathrm{N}$ \\
\hline Hourly copies distributed & 227.7 & 83.9 & 1269 \\
Number of shifts & 6.5 & 4.2 & 196 \\
Percentage of shifts worked in CHF27 & 52.5 & 23.4 & 196 \\
Fairness rating of CHF22 & 2.9 & 0.8 & 113 \\
Fairness rating of CHF27 & 3.9 & 0.9 & 113 \\
Perceived underpayment (in CHF) & 1.1 & 2.1 & 119 \\
Age (in years) & 22.5 & 4.7 & 114 \\
Male (in \%) & 27.2 & 44.7 & 114 \\
Foreigner (in \%) & 13.2 & 34.0 & 114 \\
Number of siblings & 1.4 & 0.9 & 114 \\
Secondary school (in \%) & 61.4 & 48.9 & 114 \\
Apprenticeship/vocational school (in \%) & 28.1 & 45.1 & 114 \\
Additional, further education (in \%) & 21.1 & 40.9 & 114 \\
Baccalaureate (in \%) & 67.5 & 47.0 & 114 \\
Technical school (in \%) & 23.7 & 42.7 & 114 \\
University (in \%) & 22.8 & 42.1 & 114 \\
Points returned if $1^{\text {st }}$ mover proposed $(18,6)$ & -0.56 & 1.05 & 118 \\
Points returned if $1^{\text {st }}$ mover proposed $(12,12)$ & 0.25 & 0.73 & 118 \\
Points returned if 1 $1^{\text {st }}$ mover proposed $(6,18)$ & 0.89 & 0.89 & 118 \\
& & & \\
Reciprocial individuals: & & & \\
Points returned if $1^{\text {st }}$ mover proposed $(6,18)$ & 1.25 & 0.63 & 77 \\
Points returned if $1^{\text {st }}$ mover proposed $(12,12)$ & 0.27 & 0.60 & 77 \\
Points returned if $1^{\text {st }}$ mover proposed $(18,6)$ & -0.92 & 0.81 & 77 \\
Non-reciprocal individuals: & & & \\
Points returned if $1^{\text {st }}$ mover proposed $(6,18)$ & 0.22 & 0.91 & 41 \\
Points returned if $1^{\text {st }}$ mover proposed $(12,12)$ & 0.22 & 0.94 & 41 \\
Points returned if $1^{\text {st }}$ mover proposed $(18,6)$ & 0.12 & 1.12 & 41 \\
\hline
\end{tabular}

This table describes the data used in this paper. The data come from three different sources: the sales promotion, the feedback form, and the follow-up survey that includes the moonlighting game. 196 workers were observed during the four experimental weeks; 113 of them returned the feedback form and 119 of them completed the follow-up survey. In the follow-up survey, five workers did not answer the questions on personal characteristics and one worker did not participate in the moonlighting game. 
Table 2: Randomization check for worker characteristics

\begin{tabular}{|c|c|c|c|c|c|}
\hline \multirow[b]{3}{*}{ Variable } & \multicolumn{4}{|c|}{ Treatment } & \multirow[b]{3}{*}{$p$-value } \\
\hline & \multicolumn{2}{|c|}{ CHF22 } & \multicolumn{2}{|c|}{ CHF27 } & \\
\hline & Mean & SD & Mean & SD & \\
\hline Perceived underpayment (in CHF) & 1.1 & $(2.1)$ & 1.1 & $(2.1)$ & 0.69 \\
\hline Age (in years) & 23.4 & $(5.3)$ & 23.3 & $(5.4)$ & 0.77 \\
\hline Male (in \%) & 28.1 & $(45.0)$ & 26.7 & $(44.3)$ & 0.68 \\
\hline Foreigner (in \%) & 16.1 & $(36.8)$ & 17.2 & $(37.8)$ & 0.70 \\
\hline Number of siblings & 1.4 & $(0.9)$ & 1.4 & $(0.9)$ & 0.91 \\
\hline Secondary school (in \%) & 64.8 & $(47.8)$ & 63.3 & $(48.3)$ & 0.69 \\
\hline $\begin{array}{l}\text { Apprenticeship/vocational school } \\
\text { (in \%) }\end{array}$ & 33.1 & (47.1) & 30.8 & $(46.2)$ & 0.52 \\
\hline $\begin{array}{l}\text { Additional, further education } \\
\text { (in \%) }\end{array}$ & 24.8 & $(43.2)$ & 24.2 & (42.9) & 0.85 \\
\hline Baccalaureate (in \%) & 61.8 & (48.7) & 65.8 & (47.5) & 0.27 \\
\hline Technical school (in \%) & 25.1 & $(43.4)$ & 21.1 & (40.9) & 0.22 \\
\hline University (in \%) & 24.5 & (43.1) & 21.1 & (40.9) & 0.29 \\
\hline $\begin{array}{l}\text { Points returned if } 1^{\text {st }} \text { mover } \\
\text { proposed }(18,6)\end{array}$ & -0.65 & $(1.02)$ & -0.66 & $(1.00)$ & 0.98 \\
\hline $\begin{array}{l}\text { Points returned if } 1^{\text {st }} \text { mover } \\
\text { proposed }(12,12)\end{array}$ & 0.25 & $(0.73)$ & 0.25 & $(0.68)$ & 0.88 \\
\hline $\begin{array}{l}\text { Points returned if } 1^{\text {st }} \text { mover } \\
\text { proposed }(6,18)\end{array}$ & 0.81 & $(0.90)$ & 0.86 & $(0.89)$ & 0.46 \\
\hline
\end{tabular}

Because of the within-subject design most workers participated in both treatments. It was possible, however, that some workers worked $x$ times (shifts) in treatment CHF22 and y times (shifts) in treatment CHF27. Therefore, our randomization check takes this into account, i.e., the characteristics of this worker count $x$ times for treatment CHF22 and y times for treatment CHF27. This is a very conservative randomization check because showing insignificant differences in worker characteristics across treatments would be much easier if we were to count each worker only once. The first four columns in this table show the treatment averages and standard deviations of worker characteristics. The last column contains the $p$-values ( $\mathrm{X}^{2}$ tests for binary variables and Mann-Whitney tests for non-binary variables) for the null hypothesis of perfect randomization.

Table 3: Participation at the individual level during the experiment

Dependent variable:

Number of shifts per treatment

\begin{tabular}{lcc}
\hline CHF27 & 0.189 & 0.189 \\
& $(0.130)$ & $(0.184)$ \\
Intercept & & \\
& $3.143^{* * *}$ & $3.143^{* * *}$ \\
& $(0.162)$ & $(0.092)$
\end{tabular}

Fixed effects

Worker

No

Yes

\begin{tabular}{lll}
\hline$N$ & 392 & 392
\end{tabular}

OLS estimates. Standard errors in parentheses are clustered on the individual level. The unit of observation is a worker in each treatment. The dependent variable is the number of shifts per treatment and CHF27 is an indicator variable for treatment status. The levels of significance are $* p<0.10, * * p<0.05, * * * p<0.01$. 
Table 4: Participation at the sector-day level during the experiment

Dependent variable:

CHF27

Intercept
Fraction of unfilled shifts per day

$\begin{array}{cc}0.008 & 0.008 \\ (0.028) & (0.028)\end{array}$

$0.193 * * *$

$0.193 * * *$

(0.014)

Fixed effects

$\begin{array}{lll}\text { Sector } & \text { No } & \text { Yes } \\ \text { Day } & \text { Yes } & \text { Yes }\end{array}$

\begin{tabular}{lll}
\hline$N$ & 40 & 40
\end{tabular}

OLS estimates. Standard errors in parentheses are clustered on the day level. The unit of observation is a day in each treatment. The dependent variable is the fraction of unfilled shifts per day and CHF27 is an indicator variable for treatment status. The levels of significance are $* p<0.10, * * p<0.05, * * * p<0.01$.

Table 5: Randomization check for outcomes measured after the field experiment

(1) (2) (3)

(4)

Dependent variable:

Points returned if $1^{\text {st }}$ mover proposed

\begin{tabular}{|c|c|c|c|c|}
\hline \multirow{2}{*}{ Deperiueric valianie. } & \multirow{2}{*}{ Perceived underpayment } & \multicolumn{3}{|c|}{ romits recumited II I mover proposed } \\
\hline & & $(18,6)$ & $(12,12)$ & $(6,18)$ \\
\hline Fraction of shifts in & 0.190 & 0.008 & 0.180 & 0.497 \\
\hline $\mathrm{CHF} 27$ & $(0.684)$ & $(0.431)$ & (0.299) & $(0.360)$ \\
\hline Intercept & $\begin{array}{c}0.992 * * \\
(0.431)\end{array}$ & $\begin{array}{c}-0.564 * * \\
(0.256)\end{array}$ & $\begin{array}{c}0.155 \\
(0.178)\end{array}$ & $\begin{array}{c}0.617 * * * \\
(0.214)\end{array}$ \\
\hline$N$ & 119 & 118 & 118 & 118 \\
\hline
\end{tabular}

Column (1) reports OLS estimates with robust standard errors in parentheses, while columns (2) to (4) report the estimates of seemingly unrelated regressions. Throughout all columns, the independent variable is workers' exposure to treatment CHF27 indicated as the fraction of shifts they worked under the higher wage. In column (1) the dependent variable is the perceived underpayment at the base wage, and in columns (2) to (4) the dependent variable is workers' back-transfers in the moonlighting game. The levels of significance are ${ }^{*} p<0.10,{ }^{* *} p<0.05, * * * p<0.01$. 
Table 6: Average treatment effect of the wage increase on workers' performance

(1)

(2)

Dependent variable:

$\log$ (hourly copies distributed)

CHF27

0.037

Intercept

5.608

5.269

$(0.090)^{*}$

$(0.084)^{*}$

Fixed effects

Worker

No Yes

Location

Yes

Yes

Day

Yes

Yes

$\begin{array}{lll}N & 1269 & 1269\end{array}$

OLS estimates. Standard errors in parentheses take account of serial correlation within an individual's residuals and spatial correlation among the residuals of spatially close observations on the same day (up to a distance of $3 \mathrm{~km}$ ). The dependent variable is the logarithm of the number of hourly copies distributed and serves as our performance measure. The variable CHF27 is an indicator variable for the treatment in which the workers were paid the higher wage. The levels of significance are $* p<0.10, * * p<0.05, * * * p<0.01$. 
Table 7: Robustness checks for habituation and reference point effects

(1)

(2)

Dependent variable:

$\log$ (hourly copies distributed)

CHF27

0.060

0.079

$(0.024)^{* *}$

$(0.026)^{* *}$

No. of previous CHF27 shifts

0.011

$(0.005)^{* *}$

CHF27 $\times$ No. of previous CHF27 shifts

$-0.010$

(0.006)

Intercept

5.590

5.654

$(0.088)^{*}$

$(0.094)^{*}$

Fixed effects

Worker

No

No

Location

Yes

Yes

Day

Yes

Yes

$N$

1269

645

OLS estimates. Standard errors in parentheses take account of serial correlation within an individual's residuals and spatial correlation among the residuals of spatially close observations on the same day (up to a distance of $3 \mathrm{~km}$ ). The dependent variable is the logarithm of the number of hourly copies distributed and serves as our performance measure. The variable CHF27 is an indicator variable for the treatment in which the workers were paid the higher wage. The variable "No. of previous CHF27 shifts" captures the number of previous shifts a worker had already received the higher wage. Column (2) replicates the estimation results in column (1) of Table 6 while excluding observations (and also the subsequent ones) that occurred when workers switched back to the base wage. The levels of significance are $* p<0.10, * * p<0.05, * * * p<0.01$. 
Dependent variable:

CHF27 $\log$ (hourly copies distributed)

$\begin{array}{ccc}0.039 & 0.018 & 0.005 \\ (0.019)^{* *} & (0.023) & (0.020)\end{array}$

$\mathrm{CHF} 27 \times \Delta_{\mathrm{i}}$

0.019

0.019

$(0.008)^{* *}$

$(0.007)^{* *}$

$\Delta_{\mathrm{i}}$

0.001

(0.006)

Intercept

5.619

5.633

5.317

$(0.113)^{* * *}$

$(0.108)^{* * *}$

$(0.130)^{* * *}$

Fixed effects

$\begin{array}{llll}\text { Worker } & \text { No } & \text { No } & \text { Yes } \\ \text { Location } & \text { Yes } & \text { Yes } & \text { Yes } \\ \text { Day } & \text { Yes } & \text { Yes } & \text { Yes }\end{array}$

N 722

722

722

OLS estimates. Standard errors in parentheses take account of serial correlation within an individual's residuals and spatial correlation among the residuals of spatially close observations on the same day (up to a distance of $3 \mathrm{~km}$ ). The dependent variable is the logarithm of the number of hourly copies distributed and serves as our performance measure. The variable CHF27 is an indicator variable for the treatment in which the workers were paid the higher wage. The variable $\Delta_{\mathrm{i}}$ is the difference between the wage a worker considered to be fair and the base wage. The interaction term CHF27 $\times \Delta_{i}$ thus measures the treatment effect as a function of workers' perceived underpayment. The levels of significance are $* p<0.10$, ${ }^{* *} \mathrm{p}<0.05, * * * p<0.01$. 
Table 9: Robustness check for ability effects

(1) (2) (3)

Dependent variable:

CHF27

$\log$ (hourly copies distributed)

$\begin{array}{ccc}0.018 & 0.022 & 0.007 \\ (0.023) & (0.026) & (0.028)\end{array}$

$\mathrm{CHF} 27 \times \Delta_{\mathrm{i}}$

0.019

0.021

$(0.008)^{* *}$

$(0.008)^{* *}$

$\Delta_{\mathrm{i}}$

0.001

$-0.006$

(0.006)

(0.006)

CHF27 $\times$ High-ability (= 1$)$

0.030

0.016

(0.045)

(0.046)

High-ability (= 1)

0.232

0.238

$(0.032)^{* * *}$

$(0.033)^{* * *}$

Intercept

5.633

5.410

5.427

$(0.108)^{* * *}$

$(0.111)^{* * *}$

$(0.117)^{* * *}$

Fixed effects

$\begin{array}{llll}\text { Worker } & \text { No } & \text { No } & \text { No } \\ \text { Location } & \text { Yes } & \text { Yes } & \text { Yes } \\ \text { Day } & \text { Yes } & \text { Yes } & \text { Yes }\end{array}$

N 722

722

722

OLS estimates. Standard errors in parentheses take account of serial correlation within an individual's residuals and spatial correlation among the residuals of spatially close observations on the same day (up to a distance of $3 \mathrm{~km}$ ). The dependent variable is the logarithm of the number of hourly copies distributed and serves as our performance measure. The variable CHF27 is an indicator variable for the treatment in which the workers were paid the higher wage. The variable $\Delta_{\mathrm{i}}$ is the difference between the wage a worker considered to be fair and the base wage. "High-ability" is an indicator variable for worker ability, which takes the value one if a worker's fixed effect is above the median, and zero otherwise. The interaction term CHF27 $\times \Delta_{i}$ measures the treatment effect as a function of workers' perceived underpayment, while the interaction term CHF27 $\times$ High-ability does the same for worker ability. The levels of significance are $* p<0.10,{ }^{* *} p<0.05,{ }^{* * *} p<$ 0.01 . 
Table 10: The effect of the wage increase on the performance of reciprocal vs. non-reciprocal workers

(1)

Sample:

Dependent variable:

CHF27

CHF27 $\times \Delta_{\mathrm{i}}$

Intercept

Fixed effects

Worker

Location

Day
Reciprocal workers

$\log$ (hourly copies distributed)

$\begin{array}{cc}0.000 & 0.018 \\ (0.023) & (0.023)\end{array}$

0.028

$-0.010$

$(0.012)^{* *}$

(0.009)

5.036

5.928

$(0.148)^{*}$

$(0.231)$

\begin{abstract}
N
OLS estimates. Standard errors in parentheses take account of serial correlation within an individual's residuals and spatial correlation among the residuals of spatially close observations on the same day (up to a distance of $3 \mathrm{~km}$ ). The dependent variable is the logarithm of the number of hourly copies distributed and serves as our performance measure. The variable CHF27 is an indicator variable for the treatment in which the workers were paid the higher wage. The variable $\Delta_{\mathrm{i}}$ is the difference between the wage a worker considered to be fair and the base wage. The interaction term CHF27 $\times \Delta_{i}$ thus measures the treatment effect as a function of workers' perceived underpayment. Column (1) shows the estimates for reciprocal workers, while column (2) shows the same for non-reciprocal workers. The levels of significance are $* p<0.10$, $* * \mathrm{p}<0.05, * * * \mathrm{p}<0.01$.
\end{abstract}




\section{Appendix: Follow-up survey}

\section{Scientific study on part-time employment in Switzerland}

Dear Madam or Sir

The University of Zurich selected you to participate in a scientific study. The study consists of a decision section - you can make decisions here - and a questionnaire. With your participation in this study, you will help us in better understanding the situation of part-time employees. We thus sincerely hope that you will participate. Furthermore, by participating in the study - with the careful and comprehensive completion of the decision part and the questionnaire - you can earn up to CHF 25.

Please first read the description of the decision part. Then complete the decision sheets and the questionnaire. Finally, please place the decision sheets and the questionnaire in the stamped reply envelope and return everything to us.

When we receive your reply envelope (with the decision sheets and questionnaire), we will send you the amount you earned in cash by mail. Any data we collect will be used for scientific purposes only and processed in an entirely anonymous form. We guarantee that no other person will have access to this data.

If you have any questions (e.g., about completing the decision sheets), we will be pleased to assist you. We provide information at the telephone number XXXX XX XXX XX XX or per email (parttimeworkstudy@econ.uzh.ch).

Thank you for participating!

Sincerely

Department of Economics at the University of Zurich 


\section{THE DECISION SITUATION}

\section{A. INTRODUCTION}

This part of the study is about the distribution of a monetary amount between two people and reward and punishment. You will form a group of two with another, randomly chosen person.

The other person must first decide how the monetary amount of CHF 24 will be divided between the two of you. You then have the opportunity to respond to the other person's decision by assigning him or her bonus or minus points. You may also refrain from assigning any points at all.

We guarantee anonymity in all decisions. This means that you will never learn of the other person's identity, and he or she will never learn of your identity. We also guarantee that all monetary amounts earned based on the decisions will actually be paid to you or to the other person.

\section{How can the other person allocate the CHF 24?}

The other person has three different possibilities for allocating the CHF24. He or she can

- keep CHF 18 for him/herself and give CHF 6 to you, or

- keep CHF 12 for him/herself and give CHF 12 to you, or

- keep CHF 6 for him/herself and give CHF 18 to you.

\section{What can you decide?}

You can assign the other person up to two positive or negative points, or you can do nothing, i.e., not assign any points.

Positive points: Each positive point that you assign to the other person increases his or her payment - with respect to the proposed allocation of money - by CHF 6 and costs you CHF 2. For example, if you assign two positive points, the other person's payoff is increased by CHF 12 and it will cost you CHF 4. You can thus reward the other person with positive points.

Negative points: Each negative point that you assign to the other person decreases his or her payment - with respect to the proposed allocation of money - by CHF 6 and costs you CHF 2. For example, if you assign two negative points, the other person's payoff is decreased by CHF 12 and it will cost you CHF 4 . You can thus punish the other person with negative points.

No points: In this case, the other person neither receives any positive points nor negative points. You and the other person thus earn the amounts foreseen in the proposed allocation. 


\section{B. SOME EXAMPLES}

Here you will find some examples for calculating the monetary outcomes:

\section{Example 1: the other person keeps CHF 18 for him/herself and gives you CHF 6 .}

- If, for example, you assign the other person two negative points, you will reduce his or her payoff by CHF 12 and it will cost you CHF 4 . The other person will now have $18-12=$ CHF 6 and you will earn $6-4=$ CHF 2 .

- If, for example, you assign the other person two positive points, you will increase his or her payoff by CHF 12 and it will cost you CHF 4 . The other person will now have $18+12=\mathrm{CHF} 30$ and you will earn $6-4=$ CHF 2 .

- If you do not assign any points, the other person earns CHF 18 and you earn CHF 6.

\section{Example 2: the other person keeps CHF 6 for him/herself and gives you CHF 18.}

- If, for example, you assign the other person one positive point, you will increase his or her payoff by CHF 6 and it will cost you CHF 2. The other person will now have $6+6=\mathrm{CHF} 12$ and you will earn $18-2=$ CHF 16 .

- If, for example, you assign the other person one negative point, you will reduce his or her payoff by CHF 6 and it will cost you CHF 2. The other person will now have $6-6=\mathrm{CHF} 0$ and you will earn $18-2=$ CHF 16 .

- If you do not assign any points, the other person earns CHF 6 and you earn CHF 18.

\section{PROCEDURAL DETAILS}

We ask that you determine how many positive or negative points you will assign or whether you will not assign any points for all of the 3 possible allocations the other person may propose.

- Case 1: The other person keeps CHF 18 for him/herself and gives you CHF 6

- Case 2: The other person keeps CHF 12 for him/herself and gives you CHF 12

- Case 3: The other person keeps CHF 6 for him/herself and gives you CHF 18

The other person's decision determines which case is relevant for your payment. The documentation for the study was sent to a large number of people, and we thus do not yet know which decision the other person has made. If, for example, the other person keeps CHF 12 for him/herself and gives CHF 12 to you, case 2 becomes relevant.

Please take note that there are no correct or wrong decisions in this decision situation. It is important to us that you carefully think about your decisions and that you complete all requested decisions. Please make your decisions on your own and do not discuss them with others, such as friends. Your complete anonymity is guaranteed in any case. 


\section{MONEY}

Your total income from this study consists of

1) the earnings from the decision part (up to CHF 18) and

2) a fixed sum of CHF 7 for completion of the questionnaire.

\section{How will you get your money?}

As soon as we receive the response envelopes from the participants, we will calculate your income. You will receive your earnings in cash per mail.

\section{E. YOUR DECISION SHEET}

\begin{tabular}{|c|c|c|c|c|}
\hline \multicolumn{5}{|c|}{$\begin{array}{l}\text { Your decision for case 1: } \\
\text { The other person keeps CHF } 18 \text { for him/herself and gives you CHF } 6 \text {. }\end{array}$} \\
\hline \multicolumn{5}{|c|}{$\begin{array}{l}\text { I assign the following points for this case: } \\
\text { (Please check one of the boxes below) }\end{array}$} \\
\hline 2 negative points & 1 negative point & 0 points & 1 positive point & 2 positive points \\
\hline$\square$ & $\square$ & $\square$ & $\square$ & $\square$ \\
\hline
\end{tabular}

\section{Your decision for case 2:}

The other person keeps CHF $\mathbf{1 2}$ for him/herself and gives you CHF 12.

\begin{tabular}{|c|c|c|c|c|}
\multicolumn{5}{|c|}{$\begin{array}{l}\text { I assign the following points for this case: } \\
\text { (Please check one of the boxes below) }\end{array}$} \\
\hline $\begin{array}{c}\text { 2 negative points } \\
\square\end{array}$ & $\begin{array}{c}1 \text { negative point } \\
\square\end{array}$ & 0 points & 1 positive point & 2 positive points \\
& $\square$ & $\square$ & $\square$ & $\square$ \\
\hline
\end{tabular}

\begin{tabular}{|c|c|c|c|c|}
\hline \multicolumn{5}{|c|}{$\begin{array}{l}\text { Your decision for case 3: } \\
\text { The other person keeps CHF } 6 \text { for him/herself and gives you CHF } 18 .\end{array}$} \\
\hline \multicolumn{5}{|c|}{$\begin{array}{l}\text { I assign the following points for this case: } \\
\text { (Please check one of the boxes below) }\end{array}$} \\
\hline 2 negative points & 1 negative point & 0 points & 1 positive point & 2 positive points \\
\hline$\square$ & $\square$ & $\square$ & $\square$ & $\square$ \\
\hline
\end{tabular}




\section{QUESTIONNAIRE}

Please answer the questions below with respect to your part-time employment in the last 6 months for up to 3 employers (if you have had more than 3 employers, please answer the questions with respect to the 3 most important ones; if you have had fewer than 3 employers, you can leave the corresponding fields for employer 2 and employer 3 empty).

1) Name your part-time employers in the last 6 months.

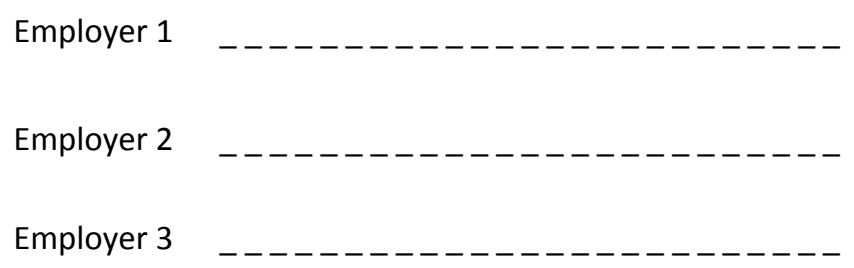

2) What tasks did you do?

I worked as with employer 1 .

I worked as with employer 2

I worked as with employer 3.

3) How many hours per week did you work with each employer?
I worked for hours per week with employer 1 .
I worked for hours per week with employer 2 .
I worked for hours per week with employer 3.

4) For how many months would you like to continue working for your present part-time employer?
I would like to work for a further months with employer 1.
I would like to work for a further months with employer 2.
I would like to work for a further months with employer 3. 
5) What where your gross hourly wages?

My gross hourly wage was $\mathrm{CHF}$ per hour with employer 1.

My gross hourly wage was $\mathrm{CHF}$ per hour with employer 2 .

My gross hourly wage was CHF per hour with employer 3.

6) What gross hourly wage would be appropriate for doing your work?

I consider the wage of $\mathrm{CHF}$ per hour to be appropriate for doing my task with employer 1 .

I consider the wage of $\mathrm{CHF}$ per hour to be appropriate for doing my task with employer 2 .

I consider the wage of $\mathrm{CHF}$ per hour to be appropriate for doing my task with employer 3 .

7) Do you find your part-time work to be exciting and fulfilling or a bit frustrating?

$\begin{array}{cccc}\begin{array}{c}\text { Very } \\ \text { frustrating }\end{array} & \begin{array}{c}\text { Somewhat } \\ \text { frustrating }\end{array} \quad \text { Neutral } & \begin{array}{c}\text { Somewhat } \\ \text { fulfilling }\end{array} & \begin{array}{c}\text { Very } \\ \text { fulfilling }\end{array}\end{array}$

Employer 1

Employer 2

Employer 3

8) How strongly do you identify yourself with your employers?

Very weakly $\begin{gathered}\text { Somewhat } \\ \text { weakly }\end{gathered}$ Neutral $\quad \begin{gathered}\text { Somewhat } \\ \text { strongly }\end{gathered} \quad$ Very strongly

Employer 1

Employer 2

Employer 3

9) Do you feel challenged in your part-time jobs?

$\begin{array}{cccc}\begin{array}{c}\text { Very } \\ \text { unchallenged }\end{array} & \begin{array}{c}\text { Somewhat } \\ \text { unchallenged }\end{array} \quad \text { Neutral } & \begin{array}{c}\text { Somewhat } \\ \text { challenged }\end{array} & \begin{array}{c}\text { Very } \\ \text { challenged }\end{array}\end{array}$

Employer 1

Employer 2

Employer 3 
10) In general, how hard was it for you to find a part-time job?

Very difficult $\begin{gathered}\text { Somewhat } \\ \text { difficult }\end{gathered} \quad$ Neutral $\quad \begin{gathered}\text { Somewhat } \\ \text { easy }\end{gathered} \quad$ Very easy

Finally, we have a few questions about you.

- Which year were you born in?

- What is your gender?

$$
\text { Male }
$$

Female

- Were you born in Switzerland?

Yes

No

- If not, for how many years have you been living in Switzerland?

I have been living in Switzerland for years.

- How many siblings do you have?

I have siblings.

- Which education levels have you completed? Please mark all of the completed courses of education and training.

$\begin{array}{lcl}\text { Primary school/mandatory education } & \square & \text { High school } \\ \text { Secondary school } & \square \quad \text { College } \\ \text { Apprenticeship/vocational school } & \square & \text { University } \\ \text { Additional, further education } & \square & \end{array}$

Thank you for participating! 


\section{References}

Abbink, K., B. Irlenbusch \& E. Renner (2000): The moonlighting game: An experimental study on reciprocity and retribution. Journal of Economic Behavior \& Organization, 42, 265-277.

Abeler, J., A. Falk, L. Goette \& D. Huffman (2011): Reference points and effort provision. American Economic Review.

Akerlof, G. A. (1982): Labor Contracts as Partial Gift Exchange. Quarterly Journal of Economics, 97, 543-569.

Akerlof, G. A. (1984): Gift Exchange and Efficiency-Wage Theory - 4 Views. American Economic Review, 74, 79-83.

Akerlof, G. A., W. T. Dickens, G. L. Perry, R. J. Gordon \& N. G. Mankiw (1996): The macroeconomics of low inflation. Brookings papers on economic activity, 1996, 1-76.

Akerlof, G. A. \& J. Yellen (1990): The Fair-Wage Effort Hypothesis and Unemployment. Quarterly Journal of Economics, 105, 255-283.

Angrist, J. D. \& J. S. Pischke (2009): Mostly harmless econometrics: An empiricist's companion. Princeton Univ Pr.

Bandiera, O., I. Barankay \& I. Rasul (2005): Social preferences and the response to incentives: Evidence from personnel data. The Quarterly Journal of Economics, 120, 917.

Bandiera, O., I. Barankay \& I. Rasul (2009): Social Connections and Incentives in the Workplace: Evidence from Personnel Data. Econometrica, 77 4, 1047-94.

Bandiera, O., I. Barankay \& I. Rasul (2010): Social Incentives in the Workplace. Review of Economic Studies, 77 2, 417-58.

Bellemare, C., S. Kroeger \& A. Van Soest (2008): Measuring inequity aversion in a heterogeneous population using experimental decisions and subjective probabilities. Econometrica, 76, 815839.

Bellemare, C., S. Kroger \& A. van Soest (2011): Preferences, intentions, and expectation violations: A large-scale experiment with a representative subject pool. Journal of Economic Behavior \& Organization, 78, 349-365.

Bellemare, C. \& B. Shearer (2009): Gift giving and worker productivity: Evidence from a firm-level experiment. Games and Economic Behavior, 67, 233-244.

Brandts, J. \& G. Charness (2004): Do Labour Market Conditions Affect Gift Exchange? Some Experimental Evidence. Economic Journal, 114, 684-708.

Cabrales, A., A. Calvó-Armengol \& N. Pavoni (2008): Social preferences, skill segregation, and wage dynamics. Review of Economic Studies, 75, 65-98.

Charness, G. (2000): Responsibility and effort in an experimental labor market. Journal of Economic Behavior \& Organization, 42, 375-384.

Charness, G., G. R. Frechette \& J. H. Kagel (2004): How Robust is Laboratory Gift Exchange? Experimental Economics, 7, 189-205.

Charness, G. \& M. Rabin (2002): Understanding social preferences with simple tests. Quarterly Journal of Economics, 117, 817-869.

Conley, T. (2008): Spatial econometrics. New Palgrave Dictionary of Economics.

Cooper, D. \& J. Kagel (2009): Other regarding preferences: a selective survey of experimental results. Handbook of Experimental Economics, 2.

Falk, A. (2007): Gift exchange in the field. Econometrica, 75, 1501-1511.

Falk, A., E. Fehr \& C. Zehnder (2006): Fairness Perceptions and Reservation Wages- The Behavioral Effects of Minimum Wage Laws. The Quarterly Journal of Economics, 121, 1347-1381.

Fehr, E. \& L. Goette (2005): Robustness and real consequences of nominal wage rigidity. Journal of Monetary Economics, 52, 779-804.

Fehr, E. \& L. Goette (2007): Do workers work more if wages are high? Evidence from a randomized field experiment. American Economic Review, 97, 298-317.

Fehr, E., G. Kirchsteiger \& A. Riedl (1993): Does Fairness Prevent Market Clearing? An Experimental Investigation. Quarterly Journal of Economics, 108, 437-460. 
Gneezy, U. \& J. List (2006): Putting Behavioral Economics to Work: Field Evidence of Gift Exchange. Econometrica, 74, 1365-1384.

Hannan, R. L., J. H. Kagel \& D. V. Moser (2002): Partial Gift Exchange in an Experimental Labor Market: Impact of Subject Population Differences, Productivity Differences, and Effort Requests on Beha. Journal of Labor Economics, 20, 923-951.

Hennig-Schmidt, H., A. Sadrieh \& B. Rockenbach (2010): In Search of Workers' Real Effort Reciprocity-a Field and a Laboratory Experiment. Journal of the European Economic Association, 8, 817-837.

Hicks, J. R. (1932): The Theory of Wages. London: Macmillan.

Hsiang, S. M. (2010): Temperatures and cyclones strongly associated with economic production in the Caribbean and Central America. Proceedings of the National Academy of Sciences, 107, 15367-15372.

Kube, S., M. Maréchal \& C. Puppe (2012): The currency of reciprocity-gift-exchange in the workplace. American Economic Review, 102, 1144-62.

Kube, S., M. Maréchal \& C. Puppe (forthcoming): Do wage cuts damage work morale? Evidence from a natural field experiment. Journal of the European Economic Association.

MacLeod, W. \& J. Malcomson (1989): Implicit contracts, incentive compatibility, and involuntary unemployment. Econometrica, 57, 447-480.

MacLeod, W. B. \& J. M. Malcomson (1998): Motivation and markets. American Economic Review, 88, 388-411.

Marshall, A. (1890): Principles of Economics. London: Macmillan.

Mas, A. \& E. Moretti (2009): Peers at work. American Economic Review, 99, 112-145.

Shapiro, C. \& J. E. Stiglitz (1984): Equilibrium Unemployment as a Worker Discipline Device. American Economic Review, 74, 433-444.

Slichter, S. H. (1929): The current labor policies of American industries. Quarterly Journal of Economics, 43, 393. 